\title{
Modification of Conductive Material AA6101 of OPGW Conductors against Lightning Strikes
}

\author{
Sedat Karabay* \\ Kocaeli University, Faculty of Engineering, Turkey
}

\begin{abstract}
In this article, failure in lightning tests and the overcoming of its destructive effects by improving the new generation of optical grounding wire (OPGW) are presented. The designed composite structure for transmission lines in Turkey is composed of six galvanized steel wires, one stainless steel tube with multiple glass fibres and 12 aluminium alloy AA6101 wires. Test samples from prototype OPGW successfully passed short circuit requirements but failed in tests of lightning strikes. Consequently, a material modification was applied by feeding $3 \%$ $A I B_{2}$ master alloy as a $9.5 \mathrm{~mm}$ rod into molten metal in the tundish when the metal flows from the melting furnace to the vertical log casting mould. Logs cast from AA6101 are used to manufacture feedstock by means of extrusion press. Impaired electrical conductivity of the AA6101 due to the presence of heavy metal impurities such as Ti, $\mathrm{Cr}$ and V should be increased to pass the tests. Following this, the transition metals were transformed into insoluble borides from solution after inoculation with $A I B_{2}$. As a result, the conductivity of wires drawn from feedstock produced by extrusion press with the modified AA6101 billets was increased from 52.5 to $57 \%$ IACS. Consequently, the modified OPGW with $A I B_{2}$ satisfied the requirements of international standards related to lightning tests.
\end{abstract}

Keywords: optical ground wire, lightning strike, AIB modification, conductivity, AA6101 feedstock, wire breakage

\section{INTRODUCTION}

The situation of overhead power transmission systems varies from year to year. Currently, the development of more reliable power transmission facilities is a serious subject for electric power utilities. Overhead ground wires (OPGW), installed on the upper portions of overhead transmission lines to protect conductors from lightning, may have their strands broken when struck by extremely powerful lightning bolts [1]. In particular, those lines passing through areas where heavy winter lightning frequently occurs or areas in which the total days on which lightning occurs are comparatively high require upgraded lightning resistant overhead ground wires to increase the reliability of the power transmission systems. Recently, the use of OPGW with a communication function has been increasing, and the roles played by OPGW have been becoming increasingly prominent. Information technology, such as web-net services, is undergoing rapid development, and this is driving demand for optical-fibre products for global optic communication link systems [2]. Two types of OPGW are generally available at present. One is a tight buffer type, in which the optical fibres are housed with tension members. The other is a loose buffer type, in which the optical fibres are loosely housed inside a tube. The representative tight buffer type called "spacer type" has an aluminium spacer inserted in the aluminium tube to suppress fibre movement. It is mainly used by Japanese domestic power companies and has proved extremely reliable in installations. The representative loose buffer type, predominantly produced in Europe and called the "stainless steel tube type" has fibres with surplus length and a jelly compound inserted into the stainless steel tube. Grease is used to fill the spaces between the tube and aluminium-clad steel or galvanized steel and aluminium alloy wires AA6101 or AA6201 in order to avoid galvanic corrosion due to different metals' contact with each other [3]. However, if the stranding of the wires is not performed perfectly, the gaps between wires cause the grease to leak during heavy rain. The grease can become hardened by sunlight or a dry atmosphere; prolonged exposure to these environmental conditions causes the grease's anti-corrosion effect to weaken [4]. This phenomenon is exacerbated in particularly harsh environments. This galvanic corrosion problem has been eliminated recently by cladding the steel fibre tube with EC grade aluminium. Using materials of the OPGW such as steel tubes, aluminium-clad steel tubes, aluminium alloy AA6101, galvanized steel wires, and aluminiumclad steel wires, manufacturing various types of combinations is possible [5]. Although new products are supplied to the conductor market to improve OPGW alternatives to pass lightning tests, the final cost is still a significant factor in selling them in developing countries.

\section{PARAMETERS OF DESIGNED AND MANUFACTURED OPGW}

A versatile loose-buffer-type OPGW has been designed and manufactured by considering the environmental conditions of Turkey and the requirements of the Turkish Electrical Authority (TEK). A cross-sectional 
view and the stranding of sub-parts are shown in Fig. 1.

a)
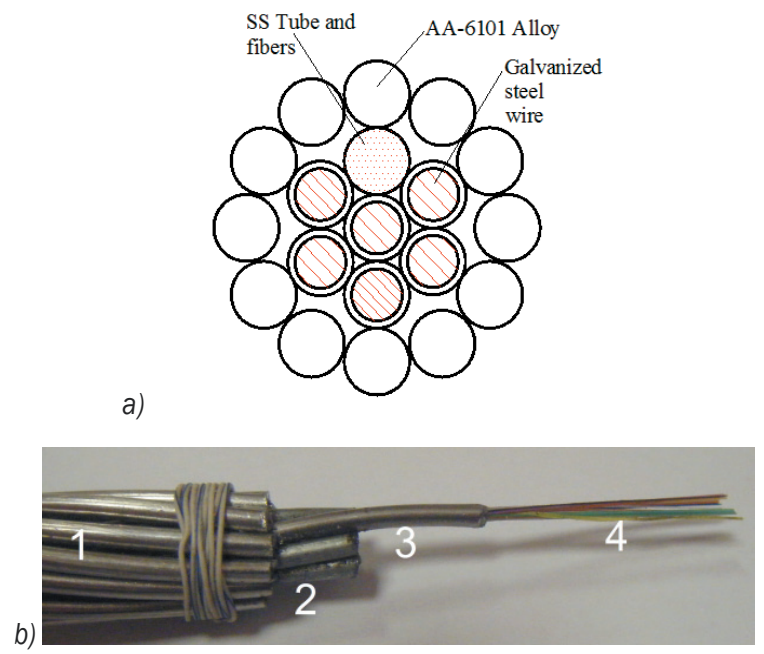

Fig. 1. a) Cross sectional view of OPGW; b) view of OPGW; (1) AA6101, (2) steel wire, (3) steel tube, (4) fibres

In design, the most important part is the conductive part, which is composed of aluminium alloy AA6101. Spectral analyses of the conductive alloy used in the manufacture of the OPGW are shown in Table 1. The main physical parameters of fibre optics located inside of the stainless steel tube are defined in Table 2. The mechanical properties of the zinc-coated steel wires in the construction given in Fig. 1 are presented in Table 3, taken from IEC 888 and ASTM B498. The zinccoated steel wires are manufactured in three grades, as regular, high strength, and extra-high strength steel wires. In the construction for TEK, high strength steel wires were used [6]. The zinc-coating is required for Class 1 of IEC 888. The optical tube used in the prototype OPGW is made of stainless steel Type 304. The tubes are manufactured by axially drawing and mechanically forming a flat strip of stainless steel around the optical fibres and laser welding the gap between the edges of the formed strip. The resulting seam is imperceptible to the unaided eye, and the resulting cylindrical tube is geometrically uniform and balanced extremely close to "perfect". Experimentally determined values per ASTM A370 for the tube's axial ultimate strength are in the range from 966 to $1379 \mathrm{~N} / \mathrm{mm}^{2}$. Some anisotropy is expected to exist due to the axial drawing of the tube. Mechanical and electrical properties of the main conductive aluminium part (unmodified aluminium) are shown in Table 4. The OPGW prototype was manufactured using the feedstock of an extrusion press with the mechanical properties shown in Table 4. Aluminium wires are tested according to IEC 104 standard to measure both mechanical and electrical parameters.

Table 1. Spectral analysis of conventional (unmodified) AA6101 sample in \% wt

\begin{tabular}{ccccccccc}
\hline $\mathrm{Mg}$ & $\mathrm{Si}$ & $\mathrm{Fe}$ & $\mathrm{Cu}$ & $\mathrm{Zn}$ & $\mathrm{B}$ & $\mathbf{C r}$ & $\mathbf{V}$ & $\mathrm{Ti}$ \\
\hline 0.55 & 0.55 & 0.25 & 0.07 & 0.08 & 0.06 & 0.03 & 0.028 & 0.026 \\
\hline
\end{tabular}

Table 2. Optical characteristics of fibres located in the stainless steel tube of OPGW

\begin{tabular}{|c|c|c|c|c|}
\hline Fibre type & \multicolumn{4}{|c|}{ Non-zero Dispersion, Shifted Single Mode Fibre } \\
\hline $\begin{array}{l}\text { Specification } \\
\text { (International } \\
\text { Telecommunication } \\
\text { Union) }\end{array}$ & \multicolumn{4}{|c|}{ ITU-T G.655 } \\
\hline $\begin{array}{l}\text { Mode field diameter } \\
\text { Cladding diameter } \\
\text { Coating diameter }\end{array}$ & & $\begin{array}{c}6 \pm 0.5 \text { (at } 1550 \\
125 \pm 1 \\
245 \pm 10 \\
\end{array}$ & & $\begin{array}{l}\mu \mathrm{m} \\
\mu \mathrm{m} \\
\mu \mathrm{m}\end{array}$ \\
\hline Wavelength & 1550 & 1530 to 1565 & 1625 & $\mathrm{~nm}$ \\
\hline $\begin{array}{l}\text { Attenuation } \\
\text { coefficient } \\
\text { Dispersion }\end{array}$ & $\begin{array}{c}0.22 \\
-\end{array}$ & 2.0 to 6.0 & $\begin{array}{c}0.27 \\
-\end{array}$ & $\begin{array}{c}\mathrm{dB} / \mathrm{km} \\
\mathrm{ps} /(\mathrm{nm} \cdot \mathrm{km})\end{array}$ \\
\hline $\begin{array}{l}\text { PMD (polarization } \\
\text { mode dispersion) }\end{array}$ & & 0.5 & & $\mathrm{ps} / \mathrm{km}^{1 / 2}$ \\
\hline
\end{tabular}

\subsection{Sensitive Part of OPGW: Fibre Optics}

An optical fibre is a flexible, transparent fibre made of glass (silica) or plastic, slightly thicker than a human hair. It functions as a waveguide, or "light pipe", to transmit light between the two ends of the fibre. Fibres are used instead of metal wires because signals travel along them with less loss and are also immune to electromagnetic interference. Optical fibres typically

Table 3. Mechanical properties of extra-high strength steel wires, IEC 888 and ASTM B498

\begin{tabular}{|c|c|c|c|c|c|c|c|}
\hline \multicolumn{2}{|c|}{$\begin{array}{l}\text { Nominal wire diameter } \\
{[\mathrm{mm}]}\end{array}$} & \multirow{2}{*}{$\begin{array}{l}\text { Diameter } \\
\text { tolerance } \\
{[\mathrm{mm}]}\end{array}$} & $\begin{array}{c}\text { Min. stress at \%1 } \\
\text { extension [MPa] }\end{array}$ & $\begin{array}{c}\text { Minimum ultimate } \\
\text { tensile strength [MPa] }\end{array}$ & \multirow{2}{*}{$\begin{array}{c}\text { Minimum ultimate } \\
\text { elongation } \\
{[\%]}\end{array}$} & \multirow{2}{*}{$\begin{array}{c}\text { Mandrel diameter } \\
\text { for wrapping test } \\
{[\mathrm{mm}]}\end{array}$} & \multirow{2}{*}{$\begin{array}{c}\text { Minimum } \\
\text { number of twists } \\
\text { in torsion test }\end{array}$} \\
\hline over & $\begin{array}{l}\text { Up to and } \\
\text { including }\end{array}$ & & \multicolumn{2}{|c|}{$\begin{array}{c}\text { Class } 1 \\
\text { zinc coating } \\
\end{array}$} & & & \\
\hline 2.25 & 2.75 & \pm 0.04 & 1410 & 1590 & 2.0 & 4 & 14 \\
\hline 2.75 & 3.00 & \pm 0.05 & 1410 & 1590 & 2.5 & 5 & 12 \\
\hline 3.00 & 3.50 & \pm 0.05 & 1380 & 1550 & 2.5 & 5 & 12 \\
\hline
\end{tabular}


include a transparent core surrounded by a transparent cladding material with a lower index of refraction. Light is kept in the core by total internal reflection. This causes the fibre to act as a waveguide. Fibres that support many propagation paths or transverse modes are called multi-mode fibres (MMF), while those that only support a single mode are called single-mode fibres (SMF). Multi-mode fibres generally have a wider core diameter, and are used for short-distance communication links and for applications in which high power must be transmitted. Some parameters used in selecting of properties of fibres are indicated in Table 2 [7].

\subsubsection{Fibre optic Wavelength}

Light is an electromagnetic wave that develops in both time and space. The development of a light wave in time is described by the period it takes for a wave's two identical points to pass; the development of light wave in space is described by wavelength [7].

\subsubsection{Attenuation}

The most common form of signal degradation is attenuation. In fact, it was only after the manufacturing of low loss silica fibre began that the field of fibre optics communication became possible. Attenuation is commonly characterized in units of decibel per kilometre. The rationale behind this choice becomes clear once we recognize that the power of an optical signal attenuates exponentially with distance as given in the Eq. (1).

$$
I(z)=I_{0} e^{\alpha_{F} z} .
$$

Here, $z$ is the distance along the length of the fibre, $I(z)$ is the optical power, $I_{0}$ is power at $z=0$ and $\alpha_{F}$ is the attenuation coefficient. Eq. (1) can alternatively be written as given in Eq. (2):

$$
10 \log I(z)=10 \log \left(I_{0}\right)-4.343 \alpha_{F} z .
$$

The relation between $\ln (x)$ and $\log (x)$ has been defined as $\ln (x)=2.302 \log (x)$. Eq. (1) provides a simple and convenient way of expressing the power loss as a function of distance. If we define $\alpha=4.343 \alpha_{F}$. Eq. (2) becomes as given in Eq. (3):

$$
P(z)_{d B m}=P(0)_{d B m}-\alpha z,
$$

where power is now expressed in units of decibelmilliwatt, and $\alpha$ is known as the attenuation coefficient of the fibre in units of decibel per kilometre [7].

\subsubsection{Dispersion}

Attenuation and dispersion are the main forms of linear degradation. Signal attenuation is mainly due to absorption and scattering, while dispersion can be a result of factors such as the waveguide properties of the fibre or wavelength dependence of the index of refraction. A decisive factor that limits the performance of optical links, especially at higher data rates, is dispersion. In general, dispersion refers to the spreading of the pulses that make up a signal as it travels along the fibre [7].

\subsubsection{Polarization Mode Dispersion (PMD)}

Another form of dispersion results from pulse broadening due to polarization of an optical pulse and the bi-refringence of fibres. To be more accurate, a given pulse may consist of different polarization components or states, and fibres do not provide an identical index of refraction for these polarization states. Factors such as stress, fibre bends, variations in the composition or geometry, and non-circularity of the fibre can preferentially cause slight changes in the effective index of refraction of fibre along different polarization directions. When the different polarization

Table 4. Test results of drawn wires from feedstock produced by extrusion of AA6101 conventional (unmodified) billets. Wires were exposed to T8 (billet homogenization $560^{\circ} \mathrm{C}, 6$ hours, wire drawing from feedstock and heat treatment of wires $175^{\circ} \mathrm{C}, 6$ hours) condition

\begin{tabular}{cccccccc}
\hline $\begin{array}{c}\text { Diameter } \\
{[\mathrm{mm}]}\end{array}$ & $\begin{array}{c}\text { Cross-section } \\
{\left[\mathrm{mm}^{2}\right]}\end{array}$ & $\begin{array}{c}\text { Resistivity } \\
{[\mathrm{ohm} \mathrm{mm} / \mathrm{m}]}\end{array}$ & $\begin{array}{c}\text { DC resistance at } \\
20^{\circ} \mathrm{C}[\mathrm{ohm} / \mathrm{km}]\end{array}$ & $\begin{array}{c}\text { Conductivity } \\
{[\% \text { IACS }]}\end{array}$ & $\begin{array}{c}\text { Breaking load } \\
{[\mathrm{N}]}\end{array}$ & $\begin{array}{c}\text { Tensile strength [N/mm²] } \\
\text { (at 250 mm length) }\end{array}$ & $\begin{array}{c}\text { Elongation at } \\
250 \mathrm{~mm}[\%]\end{array}$ \\
\hline 3.04 & 7.26 & 0.032445 & 4.470 & 53.1 & 2305.35 & 317.64 & 4.6 \\
\hline 3.05 & 7.31 & 0.032768 & 4.485 & 52.6 & 2354.40 & 322.25 & 5.1 \\
\hline 3.06 & 7.35 & 0.032836 & 4.465 & 52.5 & 2393.64 & 325.49 & 5.8 \\
\hline 3.07 & 7.40 & 0.032200 & 4.350 & 53.5 & 2403.45 & 324.71 & 4.2 \\
\hline 3.08 & 7.45 & 0.032671 & 4.385 & 52.8 & 2413.26 & 323.92 & 4.7 \\
\hline
\end{tabular}


components of an optical signal experience different indices of refraction, they propagate with different speeds, causing pulse broadening and dispersion. This effect is known as polarization mode dispersion (PMD) [7].

Standard feedstock produced with AA6101 by the method of extrusion has 40 to $45 \mathrm{HB}$ (Brinell hardness) and 130 to $150 \mathrm{~N} / \mathrm{mm}^{2}$ tensile strength. Following the cold drawing of them to the required wire diameter, tensile strength and hardness reach the range of 250 to $260 \mathrm{~N} / \mathrm{mm}^{2}$ and 50 to $55 \mathrm{HB}$, respectively. Then, heat treatment is applied at 175 ${ }^{\circ} \mathrm{C}, 6$ hours in the furnace. Thus, wires reach hardness level as 66 to $68 \mathrm{HB}$.

\section{EXPERIMENTAL STUDIES}

In the transmission lines of Turkey, several types OPGW constructions are used. Type 1 is manufactured with an SS (stainless steel) tube, loosely located fibres and $\mathrm{AlMgSi}$ wires with a combination of galvanized steel wires. In this construction, there are six galvanized steel wires, one SS tube and 12 aluminium alloy wires. Type 2 is a combination of six aluminiumclad steel wires, one SS tube and 12 AA6101 (AlMgSi) wires. Type 3 consists of one aluminium tube located in the central part and aluminium-clad steel wires helically wound around its surface. However, due to harsh environmental conditions, most of the overhead line projects are performed mainly with Type 1 and Type 2 OPGW constructions. Naturally, when the first and second types compared, the combination with $\mathrm{Al}$ clad steel wires is better than galvanized steel wires due to absent of galvanic action between different materials. However, the tensile strength of the conductor (OPGW) with Al-clad steel wire is lower than the conductor reinforced with galvanized high strength steel wires. The reason is due to the decreasing of diameter of steel wires by coating with aluminium. Therefore, it is the most popular design about the ground conductor is related to material combination with extra-high-strength galvanized steel, a loose tube and AA6101 alloy wires in transmission lines of Turkey. Moreover, its economical price also makes it popular. Therefore, according to the preferences of the Turkish Electrical Authority, the Type 1 OPGW has been designed and manufactured. The proposed structure was exposed to electrical tests. The behaviours of materials and their results after applications of electrical tests were presented at every stage. The prototype OPGW passed short circuit tests without damage to the wires. Unfortunately, most of its aluminium wires were damaged in the first trial of lightning tests. To overcome this problem, it was decided that main conductive part should be specifically improved to pass the required articles of type test specification [8]. The application methods of the type test procedure to a new designed OPGW may indicate some changes according to the product properties and specifications of different countries. The satisfaction of test conditions may be extremely demanding. Therefore, improvements are needed on some parts of proposed construction to pass the tests. However, the short-circuit current that circulates during the occurrence of a phase-to-ground fault near the substation is one of the most critical parameters for the specification of the OPGW. For a new conductor product, design and manufacturing studies must generally be performed in two stages. The first stage is to design it, theoretically. Then, having completed the manufacturing process of the prototype, prepared samples should be exposed to several tests in the laboratory by simulating environmental conditions. Among of various tests, two tests are vitally essential. These are the short circuit and lightning tests. Conductors can be damaged in seconds when exposed to these effects [9]. To pass of the type test, a product should be designed using a multi parameter equation due to adverse effects of the conductor components. In the study, two vital tests were considered, explaining how the new OPGW was developed and passed heavy electrical test requirements.

\subsection{Short Circuit Test and Results}

The objective of the short circuit test is to verify that the OPGW can withstand repeated short circuit applications without exceeding optical, physical or thermal requirements. A view of the electrical circuit at the laboratory is shown in Fig. 2. Two samples were used for the test. One sample was used to monitor the performance of the optical fibres and to observe any physical damage that might occur during the test [10]. The other sample was used only to measure the temperature at several points in the cross section of the conductor. The conductors were positioned about $1 \mathrm{~m}$ apart and $2 \mathrm{~m}$ above the ground. The conductors were electrically connected in a series so that they would be subjected to the same short circuit current. The short circuit current was provided by a high level current transformer. A separate low-level transformer was also connected to the test span. It provided a current of several hundred amperes to maintain the cable temperature at $40{ }^{\circ} \mathrm{C}$ between short circuit applications. The length of conductor between the current injection points was $10 \mathrm{~m}$ the optical fibres 
were terminated beyond each dead-end clamp. A turnbuckle was used to tension the cable to the required value. A dynamometer was used to measure the tension. The optical sample was tensioned to about $1369 \mathrm{daN}$ at $40{ }^{\circ} \mathrm{C}$. This is about $15 \%$ of the 9126 $\mathrm{daN}$ of the rated tensile strength of the conductor. The temperature in the sample was measured at three locations using three fast-responding thermocouples. They were spaced $1 \mathrm{~m}$ apart at the following locations. Thermocouple 1 was located between two aluminium alloy wires in the outer layer. Thermocouple 2 was placed between two galvanized steel wires in the first layer. Finally, Thermocouple 3 was installed to the surface of stainless steel for optical unit. The thermocouples were isolated from the other instrumentation to prevent electrical interference. For power attenuation measurement, all twenty-four fibres were spliced producing a total fibre length under test of $240 \mathrm{~m}$ ( 24 fibres $\times 10 \mathrm{~m})$. The conductor was first subjected to two low-level calibration shots and then ten "official" shots. The purpose of the calibration shots was to ensure that the current level was correct. For the official shots, the target values for the electrical parameters are given in Table 5. For each shot, the fault current and duration may vary slightly from the target values. The objective was to achieve a minimum energy level for each shot. To ensure the optical signals were stable, the power meters were powered on and operating for at least one hour before the first shot. The optical and temperature data were acquired for one hour after the tenth shot.

The conductor was maintained at $40{ }^{\circ} \mathrm{C}$ during this hold period. The optical attenuation during the short circuit applications newer increased more than $0.05 \mathrm{~dB} / \mathrm{km}$ at $1550 \mathrm{~nm}$. The maximum absolute temperature reached was $210{ }^{\circ} \mathrm{C}\left(163+47{ }^{\circ} \mathrm{C}\right)$. A section of conductor from the mid-span, and near both dead ends were dissected after the test and visually examined for damage. The results are presented in Table 6.

Table 5. Electrical parameters of target values

\begin{tabular}{ll}
\hline Parameter & Target value \\
\hline Energy & $109.5 \mathrm{kA}^{2} \mathrm{~s}$ \\
\hline Fault current & $14.8 \mathrm{kA}$ \\
\hline Duration & $0.5 \mathrm{~s}$ \\
\hline Asymmetry & Maximum possible \\
\hline Waveform & To be symmetrical after 3rd cycle \\
\hline
\end{tabular}

Table 6. Visual damage results of short circuit test

\begin{tabular}{llll}
\hline $\begin{array}{l}\text { Cable } \\
\text { Component }\end{array}$ & $\begin{array}{l}\text { Dead ends } \\
\text { (Fixed ends) }\end{array}$ & Midpoint & $\begin{array}{l}\text { Other surfaces } \\
\text { of conductor }\end{array}$ \\
\hline $\begin{array}{l}\text { Aluminium } \\
\text { Alloy Wires }\end{array}$ & $\begin{array}{l}\text { No melt and } \\
\text { breakage }\end{array}$ & $\begin{array}{l}\text { No melt and } \\
\text { breakage }\end{array}$ & $\begin{array}{l}\text { No melt and } \\
\text { breakage }\end{array}$ \\
\hline Galvanized & $\begin{array}{l}\text { No melt and } \\
\text { Steel Wires }\end{array}$ & $\begin{array}{l}\text { No melt and } \\
\text { breakage }\end{array}$ & $\begin{array}{l}\text { No melt and } \\
\text { breakage }\end{array}$ \\
\hline breakage \\
Steel Tube & No melt and & No melt and & No melt and \\
collapse & collapse & collapse \\
Fibres & No melt and & No melt and & No melt and \\
breakage & breakage & breakage \\
\hline Compound & No vaporization & No vaporization & No Vaporization
\end{tabular}

Acceptance criteria: a) the temperature rise immediately after the current pulse shall be less than $180{ }^{\circ} \mathrm{C}$ inside the optical unit; b) the attenuation increase during the tests shall be less than $1 \mathrm{~dB} / \mathrm{km}$. There shall be no change in attenuation after the cable has cooled down to $40{ }^{\circ} \mathrm{C}$; c) there shall be no irreversible birdcaging. The cable and hardware shall be dissected midpoint of the span. Each separable component of the cable shall be inspected.

\subsubsection{Discussion of Short Circuit test Results}

There was no sign of birdcaging, excessive wear, discoloration, deformation or other sign of breakdown.

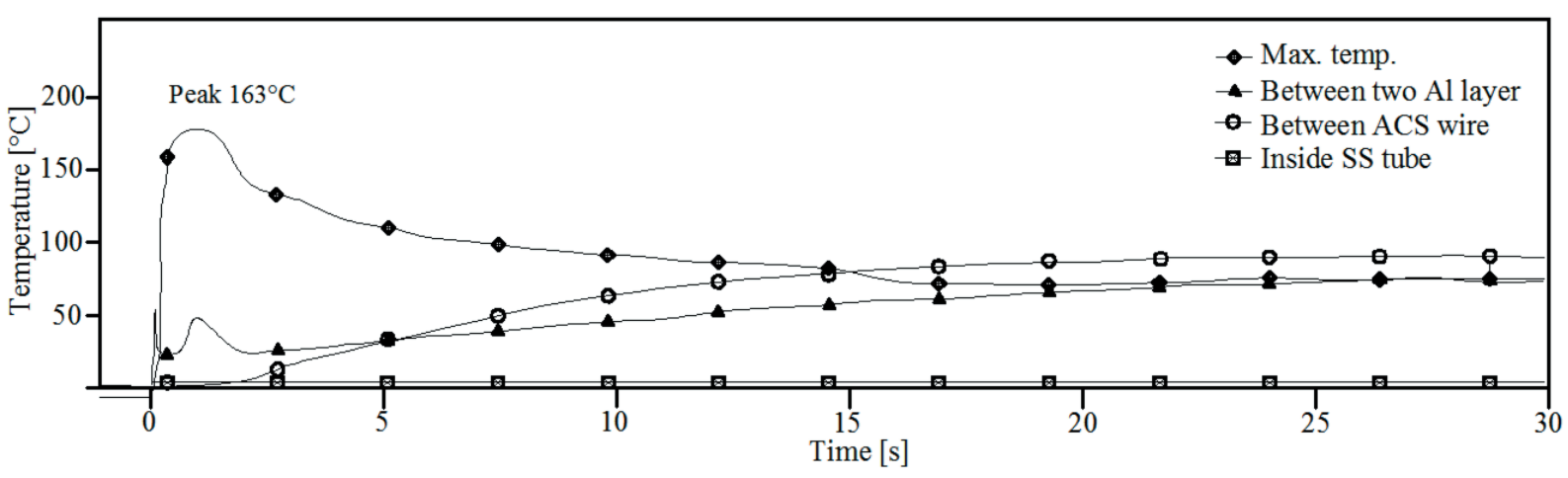

Fig. 2. Conductor temperature rise during short circuit 


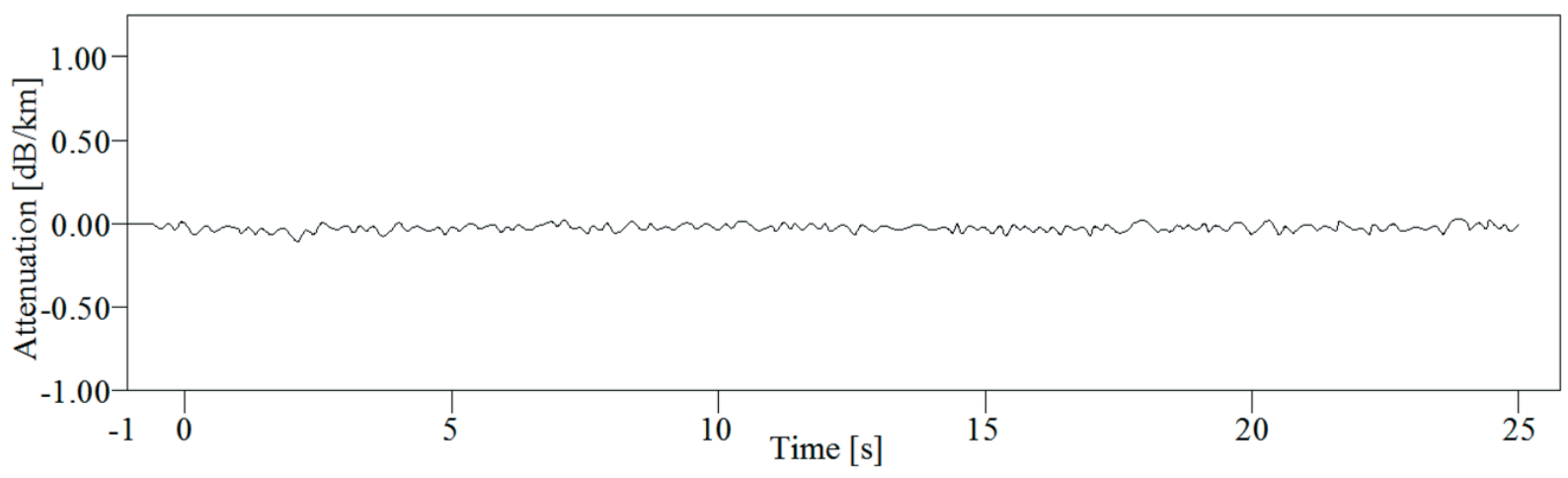

Fig. 3. Variation in optical attenuation during short-circuit

Results related to temperature fluctuation in OPGW and attenuation of fibres can be seen by examining the records given in Figs. 2 and 3, respectively. The maximum temperature rise recorded was measured as $163{ }^{\circ} \mathrm{C}$ at the outer layer (Max. $163<180{ }^{\circ} \mathrm{C}$ ). The results of conductor components after test have been summarized in Table 6. Consequently, the design study and type test experiments verified each other. Accordingly, the selected materials and construction type of OPGW satisfied all articles related to the short circuit type tests.

\subsection{First Lightning Test}

The samples with lengths of $50 \mathrm{~m}$ were clamped into the test stand, as shown in Fig. 4. The OPGW was prepared with a protective spiral and a guy spiral. With a mechanical power drive in connection with a tension meter, the wire tension was adjusted to $20 \%$ of the $17.9 \mathrm{kN}$ of the calculated breaking load (UTS) of the conductor under test. For the purpose of mechanical damping during the lightning test, two springs were installed at each end of the mechanical system, including the test object. The upper rod electrode is vertically adjustable and placed above the OPGW. It is rounded at the end facing the arc and has a diameter of $25 \mathrm{~mm}$. With a wire (copper, diameter 0.1 $\mathrm{mm}$ ), the lightning current is ignited. The ground wire under test is symmetrically connected to the power source in order to minimize the magnetic force on the arc. To test the behaviour of the OPGW under the most difficult conditions, five tests were carried out on the test sample at different places. The electrode gap was adjusted to $80 \mathrm{~mm}$. The cable was initially stressed with a mechanical load. The amplitude of the arc current was adjusted to $200 \mathrm{~A}$. The duration of the arc was $500 \mathrm{~ms}$ (Total charge 100 Coulomb according to IEC 60794-1-2 test procedure H2). Views of the surfaces of the OPGW after application of lightning charge are presented in Fig. 5

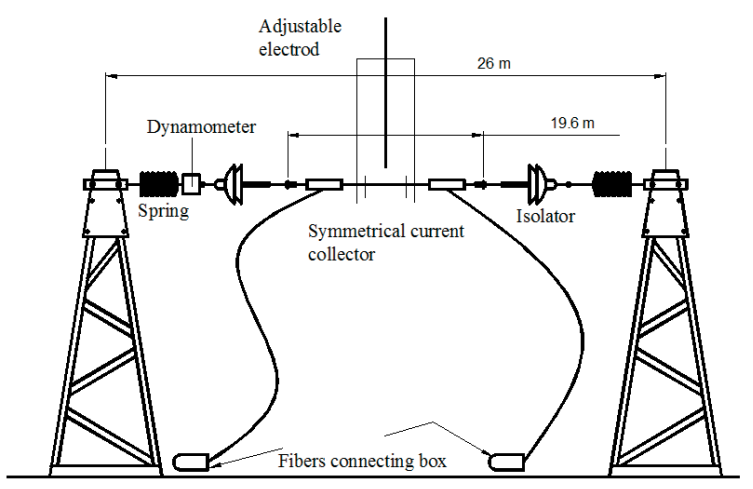

Fig. 4. Schematic illustration of lightning test stand

\subsubsection{Discussion of First Lightning Test Results}

Having completed ignition of lightning charge, the conductor must withstand $75 \%$ of the rated tensile stress (RTS). The RTS of the OPGW is $8950 \mathrm{kN}$. This means that the broken $\mathrm{Al}$ wires at each trial never number more than nine wires, owing to restriction on the complete strength of OPGW. However, in the experiments 9 to $10 \mathrm{Al}$ wires were destroyed due to lightning arc. Damaged strands due to spot melting and breaking of OPGW are presented in Figs. 5a and b. Although considerably destroying the wires located on the outer layer of OPGW, as seen in Fig. 5, the conductor (OPGW) can still withstand $75 \%$ of the RTS. However, the specification of Turkish Electrical Authority indicates that complete resistance of the conductor must not increase $20 \%$ over the initial value after application of the lightning charge. This rule restricts the broken wires in the OPGW conductor to "3 wires" after test. For the elimination of excessive 

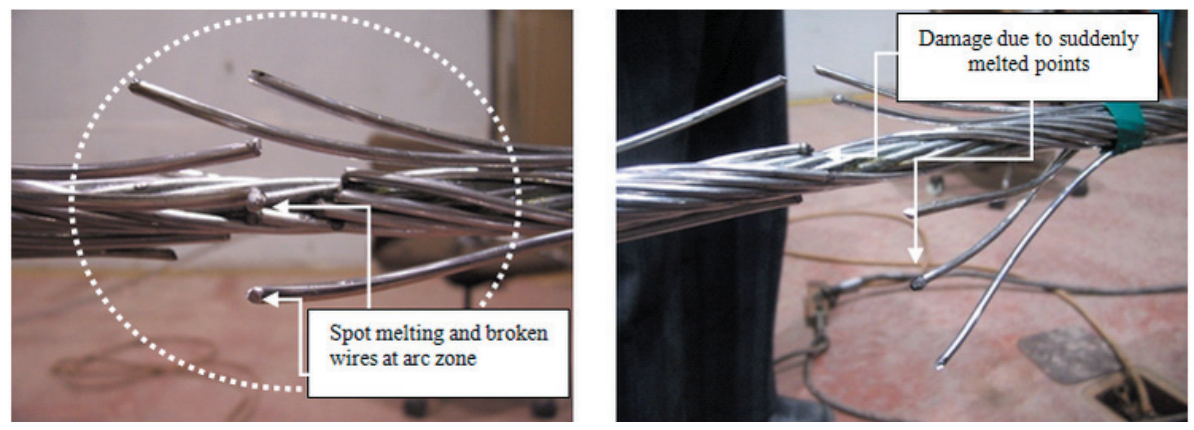

Fig. 5. View of melted and broken wires after lightning test

wire breaking, either the diameter of the wires or the number of wires or the conductivity of metal must be increased. However, the diameter of the conductor is not increased due to compatibility of available grounding wires in the transmission lines. Therefore, modification of the conductive material to increase conductivity was chosen in order to overcome the destructive effects of lightning charges.

\subsection{Modification of Aluminium by Inoculating AIB $_{2}$}

When the OPGW samples are exposed to lightning, as seen in Fig. 5, the breaking of excessive wires owing to spot melts can be detected easily. It is clearly understood that the material needs some improvement in order to withstand the effects if lightning. The first idea for the solution of the problem is to increase the melting point of the material by using some additives into the molten material [11]. However, the conductive metal should also satisfy $52.5 \%$ IACS of minimum conductivity level, as presented in Table 7 . In other words, Table 5 applies a restriction in the increasing of material strength of the conductive part with high strength alloying elements to resist lightning energy.

Table 7. Expected minimum tensile strength and conductivity of AA6101 wires after T8, IEC 104

\begin{tabular}{ccc}
\hline Diameter of wire & Conductivity & Tensile strength \\
\hline$\leq 3.5 \mathrm{~mm}$ & $52.5 \%$ IACS & $325 \mathrm{MPa}$ \\
\hline$\leq 3.5 \mathrm{~mm}$ & $53.0 \%$ IACS & $295 \mathrm{MPa}$ \\
\hline
\end{tabular}

Some additives fed into the molten material to increase the melting point adversely affect the material's electrical properties. It is well known that impurities available in the molten metal bath such as Ti, Cr, V, and $\mathrm{Zr}$ decrease conductivity or increase resistance [12]. These impurities act a barrier to the flowing atoms in the material. If the conductivity of the material is high, the current flow will be exceptionally fast, so heating of the material will be lower. It was determined experimentally by Matthiessen that the increase in the electrical resistivity of a metal due to the presence of a small amount of another metal in the solid solution is independent of the temperature [12]. Accordingly, the total electrical resistivity of an impure metal may, therefore, be separated into additive contributions: $\rho_{0}$, residual resistivity caused by the scattering of electrons by impurity atoms and lattice defects and is temperature independent but dependent on the impurity concentration (c); and $\rho_{i}$, the temperature-dependent intrinsic resistivity arising from the scattering of electrons by lattice waves or phonons. $\rho(\mathrm{c}, \mathrm{T})$ defines the total resistance of the metal. The relation including explained parameters is defined in the Eq. (1) [13]:

$$
\rho(c, T)=\rho_{0}(c)+\rho_{i}(T) .
$$

Consequently, the electrical conductivity of pure metals is reduced by impurities and structural imperfections. It is extremely important to minimize resistance losses in power transmission applications by removing as many such imperfections as possible. The rule of Nordheim states that in the case of dilution, the residual resistivity is proportional to the impurity concentration [13]. When present in a precipitated rather than solute form, the impurities cause a much smaller reduction in conductivity. $\mathrm{AlB}_{2}$ and $\mathrm{AlB}_{12}$ phases of aluminium boron master alloys show clustering to precipitate impurities, in particular titanium, vanadium, chromium, and zirconium in aluminium (99.6 and 99.7\%) and also aluminium alloys such as AA6101 and AA6201 [14]. AlB $_{2}$ can be added into aluminium as a master alloy.

There are two ways to produce feedstock for production of the conductor. In OPGW constructions, the aluminium component is composed of drawn wires from feedstock of AA6101 or AA6201 alloys. Both of the feedstock are manufactured by extrusion or continuous casting and then exposed to T8 heat 
treatment. The AA6101 feedstock of the OPGW presented in the study has been produced by an extrusion process using 1600 ton extrusion press; 3\% $\mathrm{AlB}_{2}$ in rod form (9.5 mm dia.) is added to the molten aluminium alloy in the tundish when the alloy is cast as $6 \mathrm{~m}$ vertical $\log$. Thus, heavy metals $\mathrm{Ti}, \mathrm{V}, \mathrm{Cr}$, and $\mathrm{Zr}$ are transformed into the fine borides as $\mathrm{CrB}_{2}$, $\mathrm{VB}_{2}, \mathrm{TiB}_{2}$, and $\mathrm{ZrB}_{2}$, which no longer influence on conductivity [15]. Moreover, the view of the AA6101 structure exposed to precipitation hardening at $175^{\circ} \mathrm{C}$ for six hours is presented in Fig. 6.

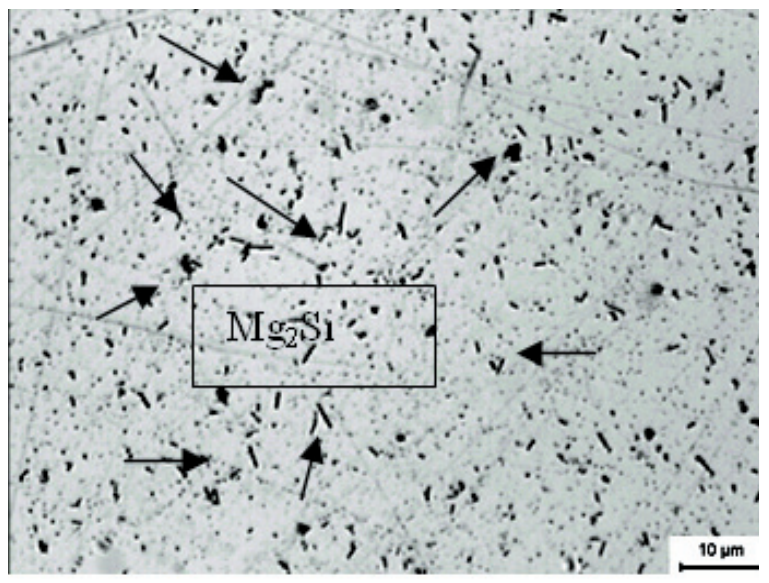

Fig. 6. View of AA6101 structure after modification with AIB2 and treated at $175^{\circ} \mathrm{C} / 6$ hours

In Fig. 6, the distribution of $\mathrm{Mg}_{2} \mathrm{Si}$ precipitations is seen to be remarkably uniform after T8 treatment of the wires drawn from the extruded feedstock at $510{ }^{\circ} \mathrm{C}$. Thus, their contribution to the strength of the material is at an acceptable level according to Table 8. Moreover, any detrimental effect of $\mathrm{AlB}_{2}$ on strength, elongation and processing of the modified material were not determined after application of heat treatment. Modified AA6101 was exposed to different temperatures and treatment times in the furnace, and both changes of tensile stress and conductivity were determined. Fig. 7 indicates the optimum temperature and tensile stress combination for $6 \mathrm{~h}$. It also shows combinations of over-aging versus tensile stress at upwards temperatures of $175{ }^{\circ} \mathrm{C}$. Having completed sample testing of the OPGW, it was determined that satisfying of the short circuit criteria was realized without encounters any problems. Moreover, lighting and short circuit tests show some similar effects in the sense of conductive metal. Therefore, to determine the degree of influence of $\mathrm{AlB}_{2}$ on conductive material, we decided to design some theoretical constructions using the base configuration shown in Fig. 1 but changing some material components, such as the clad steel and clad tube. Then, calculations of conductivity increases of the wires inoculated with $\mathrm{AlB}_{2}$ were performed on the complete conductor. Thus, increasing of current carrying capacity of base configurations was determined for several alternatives. As a consequence, if the conductivity of the conductive material is increased, the short circuit capacity of the OPGW is increased radically. In theoretical calculations, Eqs. 2 and 3 were used. In Table 8, mechanical and electrical properties of the wires prepared from the modified feedstock were presented.

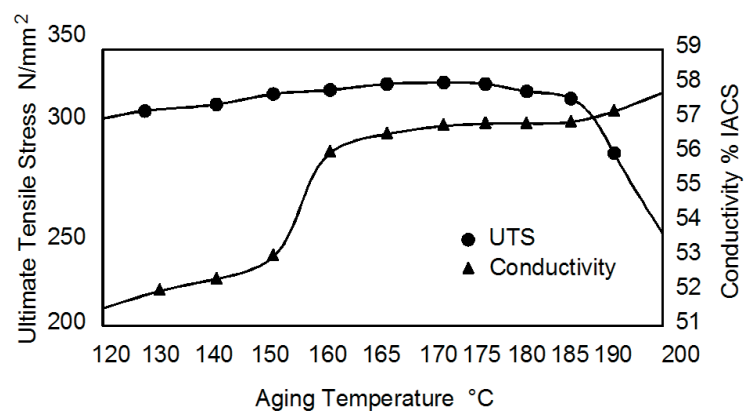

Fig. 7. Precipitation hardening of AA6101 wires and changing of temperature versus to tensile stress and conductivity

From the theoretical analysis, it has been proved that increasing the short circuit capacity by decreasing the internal resistance of the material gives durability to the conductor when affected by lightning arcs.

Table 8. Electrical and mechanical properties of AA6101 wires drawn from the extrusion feedstock produced by billets modified with AIB2 (homogenization of billets $560^{\circ} \mathrm{C}, 6$ hours). Wires are heat treated at $175^{\circ} \mathrm{C}, 6$ hours. Tests were performed according to IEC 104 and IEC 1089 standards

\begin{tabular}{cccccccc}
\hline $\begin{array}{c}\text { Diameter } \\
{[\mathrm{mm}]}\end{array}$ & $\begin{array}{c}\text { Cross-section } \\
{\left[\mathrm{mm}^{2}\right]}\end{array}$ & $\begin{array}{c}\text { Resistivity } \\
{[\mathrm{Ohm} \mathrm{mm} / \mathrm{m}]}\end{array}$ & $\begin{array}{c}\text { DC resistance at } \\
20^{\circ} \mathrm{C}[\mathrm{ohm} / \mathrm{km}]\end{array}$ & $\begin{array}{c}\text { Conductivity } \\
{[\% \text { IACS }]}\end{array}$ & $\begin{array}{c}\text { Breaking load } \\
{[\mathrm{N}]}\end{array}$ & $\begin{array}{c}\text { Tensile strength } \\
{\left[\mathrm{N} / \mathrm{mm}^{2}\right]}\end{array}$ & $\begin{array}{c}\text { Elongation at } \\
250 \mathrm{~mm}[\%]\end{array}$ \\
\hline 3.04 & 7.26 & 0.030231 & 4.165 & 57.0 & 2403.45 & 331.08 & 6.0 \\
\hline 3.05 & 7.31 & 0.030218 & 4.136 & 57.1 & 2432.88 & 332.85 & 6.4 \\
\hline 3.06 & 7.35 & 0.030262 & 4.115 & 57.0 & 2403.45 & 326.77 & 7.0 \\
\hline 3.07 & 7.40 & 0.030201 & 4.080 & 57.1 & 2413.26 & 325.98 & 7.2 \\
\hline 3.08 & 7.45 & 0.030175 & 4.050 & 57.1 & 2423.07 & 325.20 & 7.4 \\
\hline
\end{tabular}


The calculation of the short-circuit current capacity is based on the assumption that no external heat flow would develop (adiabatic heating process).

$$
I t^{1 / 2}=K_{c} A \text {. }
$$

The parameter $A$ is the minimum cross-sectional area of the protective earth conductor $\left[\mathrm{mm}^{2}\right] . I^{2} t$ is the energy of the short circuit. $K_{c}$ is the adiabatic temperature rise constant. The constant $K_{c}$ is made up of the material properties and temperature range of the conductor material. IEC 60364-5-54 and BS 7454 give some guidance on the calculation of the constant $K_{c}$, according to the following equation:

$$
K_{c}=\left[\left(\frac{Q_{c}(\beta+20)}{\rho_{20}}\right) \cdot \ln \left(1+\frac{\left(\theta_{f}-\theta_{i}\right)}{\left(\beta-\theta_{i}\right)}\right)\right]^{1 / 2},
$$

where $Q_{c}$ is the volumetric heat capacity of the conductor material at $20{ }^{\circ} \mathrm{C}\left(\mathrm{J} /{ }^{\circ} \mathrm{C} \mathrm{mm}\right) . \beta$ is the reciprocal of the conductor temperature coefficient of resistivity at $0{ }^{\circ} \mathrm{C} . \rho_{20}$ is the electrical resistivity of the conductor material at $20{ }^{\circ} \mathrm{C}[\Omega \mathrm{mm}] . \theta_{i}$ and $\theta_{f}$ are the conductor initial and final temperatures respectively $\left({ }^{\circ} \mathrm{C}\right)$. Some coefficients used in the equation can be selected from the Table 9. Thus, samples of the second trial for testing of the construction against to lightning were prepared from the material given in Table 8 . The minimum lay length was used to increase material contact surfaces so that stranding of wires was performed tightly.

Table 9. Physical parameters of the earth conductor (OPGW) materials, IEC 60364

\begin{tabular}{cccc}
\hline Material & $\beta$ & $Q_{c}$ & $\rho_{20}$ \\
\hline Aluminum & 228 & $2.5 \times 10-3$ & $28.264 \times 10-6$ \\
\hline Steel & 202 & $3.8 \times 10-3$ & $138 \times 10-6$ \\
\hline
\end{tabular}

\subsection{Second Trial of Lightning Test and Results}

Having completed the manufacturing of the OPGW with new improved wires, samples were prepared for lighting tests again. The test procedure was applied as explained previously. The test was performed five times and results were tabulated in Table 10. Views of strands of OPGW after application of lightning charge are given in Fig. 8.
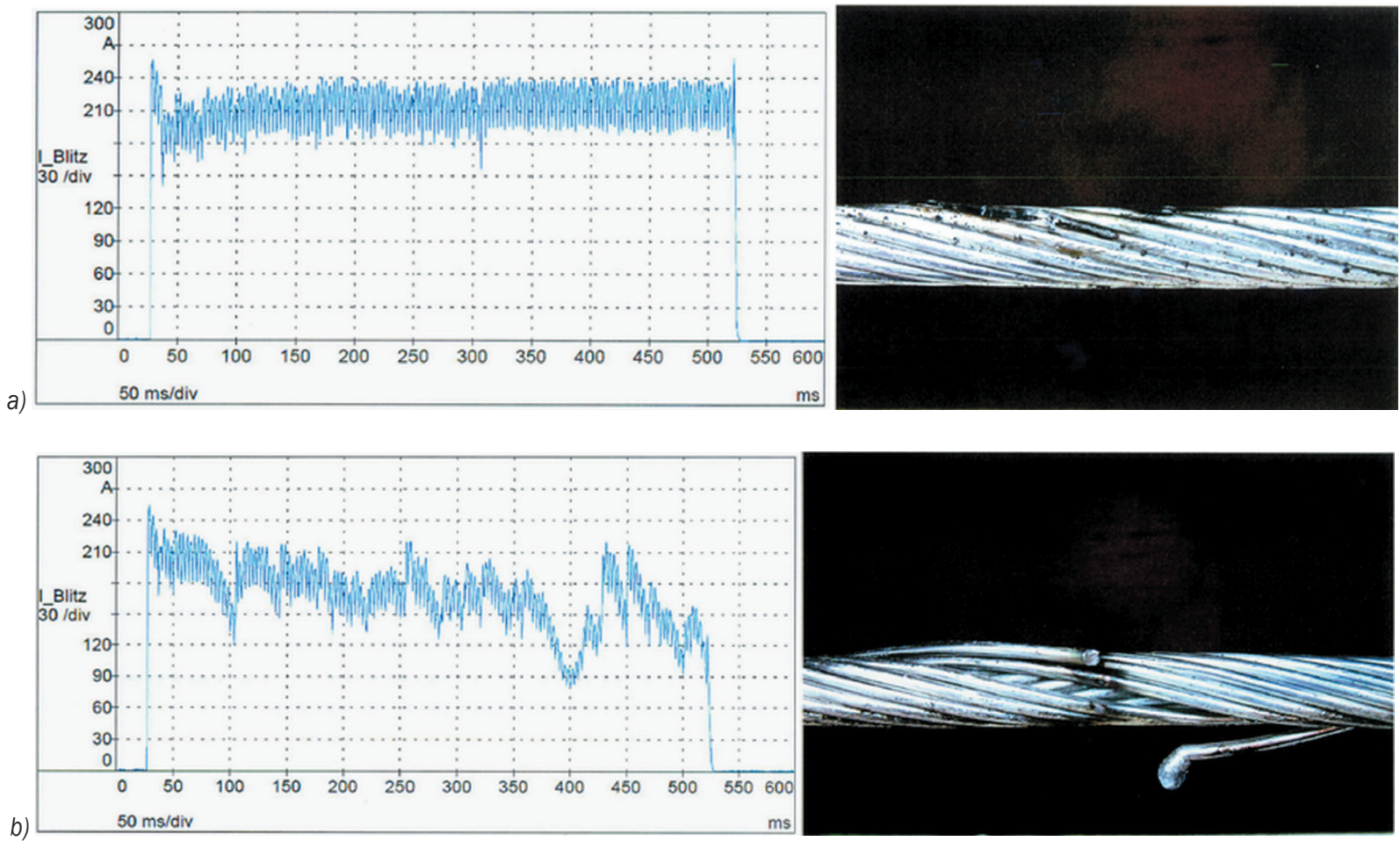

Fig. 8. a) View of slightly damaged surface of improved OPGW after application of second lightning trial, b) view of limited damage and broken wire due to spot melting of conductor surface of improved OPGW after application of second lightning trial 


\subsubsection{Discussion of Secondary Lightning Test Performed with Modified Material AA6101}

Analysis of view of Fig. 8 and results summarized in Table 10 show that broken wires owing to the lightning effect decrease sharply to one or two. The main reason this is due to the high conductivity of the modified wires compared to unmodified aluminium alloy AA6101. Naturally, some damage related to individual wires on the outer layer of the OPGW occurred. However, the numbers of the broken wires in the second lightning test are extremely low when compared to that of first lightning tests. Therefore, it satisfied both strength restriction 75\% RTS and the restriction related to resistance increases of the initial resistivity of the conductor as $20 \%$. The permissible resistance increasing after application of lightning arc allows a maximum of three wires broken (see the last two lines in Table 10).

Table 10. Results related to second trial lighting tests of OPGW manufactured from improved $A A 6101$ alloy with $A I B_{2}$

\begin{tabular}{|c|c|c|c|c|c|}
\hline & Test 1 & Test 2 & Test 3 & Test 4 & Test 5 \\
\hline$U[\mathrm{~V}]$ & 1045 & 1042 & 1047 & 1041 & 1053 \\
\hline$I[\mathrm{~A}]$ & 172.7 & 220.7 & 216.1 & 221.3 & 226.8 \\
\hline$Q[C]$ & 89.4 & 110.2 & 107.5 & 110.2 & 112.9 \\
\hline$t[\mathrm{~ms}]$ & 500.4 & 500.8 & 497.3 & 497.9 & 498.0 \\
\hline $12 t\left[\mathrm{kA}^{2} \mathrm{~s}\right]$ & 14.4 & 24.4 & 23.2 & 24.4 & 25.6 \\
\hline Temperature $\left[{ }^{\circ} \mathrm{C}\right]$ & 17.1 & 16.8 & 17.3 & 16.7 & 16.3 \\
\hline Melted wire outer layer & 1 & 2 & 2 & 1 & 3 \\
\hline Broken wires outer layer & 1 & 2 & 1 & 1 & 2 \\
\hline Melted wire inner layer & 0 & 0 & 0 & 0 & 0 \\
\hline $\begin{array}{l}\text { Visible damage of the } \\
\text { optical unit }\end{array}$ & No & No & No & No & No \\
\hline Remaining UTS [\%] & 97.56 & 95.12 & 97.56 & 97.56 & 95.12 \\
\hline $\begin{array}{l}\text { Electrical Resistance } \\
\text { Change }\end{array}$ & 8.33 & 16.67 & 8.33 & 8.33 & 16.67 \\
\hline
\end{tabular}

\section{CONCLUSIONS}

The lightning resistance of the designed overhead ground wire has been considerably improved while maintaining mechanical and electrical properties. The experiments clearly indicate that the aluminium component AA6101 of the composite conductor OPGW can be modified to obtain the best conductivity properties by adding the $\mathrm{AlB}_{2}$ compound into the molten metal in the casting of logs. If the diameter of the OPGW is increased, then the conductive area is increased. As a result, the conductor gains lightning resistance. The strategy developed for improvement with $\mathrm{AlB}_{2}$ is (due to some limitations) related to sagging properties of the available transmission lines in the country. However, the increasing of the diameter of the OPGW causes incompatibility with regards to sagging to available grounding conductor working in transmission line. Therefore, the best way for the solution of broken wires is to increase the conductivity of the material to resist lightning arcs. Inoculation for improving of AA6101 should be applied at the casting stage of logs. A master compound of $3 \%$ $\mathrm{AlB}_{2}$ in rod form ( $9.5 \mathrm{~mm}$ dia.) should be fed into the flowing metal stream in the tundish located between melting furnace and vertical casting unit. A reaction time of one to two minutes is adequate for boride precipitation. When $\mathrm{AlB}_{2}$ is added to the melt, the most probable compounds that can be formed are diborides as $\mathrm{TiB}_{2}, \mathrm{ZrB}_{2}, \mathrm{CrB}_{2}$ and $\mathrm{VB}_{2}$. The risk of inadequate dispersion with a slow-moving metal stream can be avoided by applying local restrictions in the tundish to increase the metal viscosity (increase speed). Thus, the best mixing of $\mathrm{AlB}_{2}$ with $\mathrm{AA} 6101$ is obtained.

Moreover, the stranding of aluminium wires onto a core consisting of steel wire and SS tube must be performed tightly by decreasing lay length up to 1 to $2 \mathrm{~cm}$ to prevent clearance between of the wires. This process was performed by changing the distance between the circular plates of the pre-forming unit. The pre-forming head consists of three circular plates with the rollers mounted on its periphery. The three circular plates are mounted on a screw. The distance between first and third plates indicates the lay length of the conductor. In order to avoid spring back of the wires, 0.6 to $0.7 \times$ lay length is adjusted. Thus, clearances of the alloy wires of OPGW are eliminated. Therefore, electrical arcs occurr between the wires when it is liable to lightning strikes are blocked.

Moreover, some authors [4] and [5] propose new constructions. They explain that the conductivity of aluminium part of OPGW should be reinforced with aluminium clad steel wires and clad steel tubes or aluminium extruded tube. The high temperature of the lightning strike is the exterior reason for wire breakage, and the lower melting point of the wire is the interior reason for wire breakage. However, the cladding process is more expensive than a zinc coating applied to steel wires. The usage of clad steels substantially increases the price of the product. This is the most decisive parameter for developing countries, due to increasing of the investment budget. Therefore, developing countries apply some restrictions on the final cost of the product. The market price of $\mathrm{Al}$ clad steel wire is around $\$ 1900$ to 2100 per ton. In contrast, the price of zinc-coated steel wires is $\$ 800$ / ton. The kilometric weight of the OPGW considered 
in the study is about $621 \mathrm{~kg} / \mathrm{km}$. If clad steel wires are used in the design of the OPGW to increase the conductivity area, the additional kilometric cost for complete conductor is around $\$ 420$ per $\mathrm{km}$. However, the modification process explained here by adding a $3 \% \mathrm{AlB}_{2}$ compound as $3 \mathrm{~kg}$ per ton AA6101 is the cheaper way to increase the conductivity of the OPGW. The price of the $3 \% \mathrm{AlB}_{2}$ master alloy is around $€ 8$ to 10 per $\mathrm{kg}$. It causes additional cost as $\$ 9.65 / \mathrm{km}$ for modification of per $\mathrm{km}$ OPGW. This cost difference considerably expresses the power of the method described in the study.

In conclusion, the modified OPGW conductor with $\mathrm{AlB}_{2}$ passed the lightning test and satisfied all the electrical and mechanical test requirements of international standards.

\section{REFERENCES}

[1] Alvim, M.G. (2004). Improved Performance of OPGW under Lightning Discharges in Brazilian Regions with a High Keraunic Level. CIGRE, 40th Session, Paris, p $1-9$.

[2] Yokoya, M., Katsuragi, Y, Nagata, Y., Asano, Y. (1994). Development of Lightning Resistant Overhead Ground Wire. IEEE Transaction on Power Delivery, vol. 9, no. 3, p. 1517-1523, DOI:10.1109/61.311216.

[3] Criasafulli, C.A.; Spoor, D.J. (2008). A Case Study on the Appropriate Selection of Optical Ground Wire. Australasian Universities Power Engineering Conference, paper 106, p. 1-5.

[4] Tsuji, T., Namekawa, Y., Fukasawa, T., Momomota, S. (2001). New OPGW with Aluminum Covered Stainless Steel Tube. Hitachi Cable Review, no. 21.

[5] Tiancang, D., Zheng, Y., Xia, W. (2006). Study on the Problem of Lightning Strike OPGW. International Conference on Power System Technologies, p. 1-4.

[6] Goda, Y., Shigenu, Y., Watanabe, S. (2004). Melting and Breaking Characteristics of OPGW
Strands by Lightning. IEEE Transaction on Power Delivery, vol. 19, no. 4. p. 1734-1739, DOI:10.1109/ TPWRD.2004.832410.

[7] Azadeh, M. (2009). Fiber Optic Engineering. Springer Dordrecht Heidelberg London, p. 125-155, DOI:10.1007/978-1-4419-0304-4.

[8] Jakl, F.. Jakl, A. (2000). Effect of Elevated Temperatures on Mechanical Properties of Overhead Conductors Under Steady State and Short-Circuit. IEEE Transaction on Power Delivery, vol. 15, no. 1, DOI:10.1109/61.847258.

[9] Torvath, T. (2004). Standardization of Lightning Protection Based on the Physics on the Tradition. Journal of Electrostatics, no. 60, p. 265-275, DOI:10.1016/j.elstat.2004.01.008.

[10] Chrisholm, W.A; Levine, J.P., Chowdhuri, P. (2001). Lightning Arc Damage to Optical Fiber Ground Wires (OPGW): Parameters and Test Methods. Proceedings of Power Engineering Society, vol. 1, p. 88-93.

[11] Guavac, S.J., Nimrihter, M.D., Geric, Lj. R. (2007). Estimation of Overhead Line Condition. Electrical Power System Research, no. 78, p. 556-583.

[12] Karabay, S., Uzman, I. (2005). A Study on the Possible Usage of Continually Cast Aluminium 99.6\% Containing High Ti, V, and Cr Impurities as Feedstock for the Manufacturing of Electrical Conductors. Materials and Manufacturing Process, no. 20, p. 231243, DOI:10.1081/AMP-200041884.

[13] Kittel, C. (1996). Solid State Physics, 7th ed.. John Wiley \& Sons, Inc., New York, p. 161-162.

[14] Karabay, S., Uzman, I. (2005). Inoculation of Transition Elements by Addition of AlB2 and AlB12 to Decrease Detrimental Effects on the Conductivity of $99.6 \%$ Aluminium for Manufacturing of Conductor. Journal of Material Processing Technology, no. 160, p. 174182, DOI:10.1016/j.jmatprotec.2004.06.015.

[15] Setzer, W.C., Boone, G.W. (1992). The use of aluminum boron master alloys to improve electrical conductivity. Light Metals, p. 837-844. 